\title{
Os investimentos em transportes do Programa de Aceleração do Crescimento (PAC) e o efeito multiplicador brasileiro a partir do governo Lula da Silva
}

\author{
[The Growth Acceleration Program (PAC)'s investments in transportation and the \\ Brazilian multiplication effect since Lula da Silva's government] \\ Márcio Rogério Silveira, Alessandra dos Santos Julio* \\ Universidade Federal de Santa Catarina - UFSC - Brasil, Universidade Estadual Paulista - UNESP - Brasil
}

Submitted 24 Aug 2012; received in revised form 23 Jan 2013; accepted 28 Jan 2013

\begin{abstract}
Resumo
0 transporte é condição necessária à circulação do capital, portanto, este também é basilar na produção e reprodução do espaço. Com base nesta assertiva o artigo objetiva realizar uma análise da relação das inversões em capital fixo, particularmente obras de transporte, feitas pelo Governo Federal, através dos investimentos do Programa de Aceleração do Crescimento - PAC. Os investimentos em transporte, realizados através de intervenção estatal, podem inferir positivamente no volume do emprego e na demanda efetiva, contribuindo para o desenvolvimento econômico-social. Esta análise se baseia na teoria do efeito multiplicador e da dialética da capacidade ociosa como formas de aprender a relevância dos investimentos públicos em obras de infraestrutura de transporte. Tal tarefa trouxe consigo a possibilidade de demonstrar quais os entraves à execução de grandes investimentos públicos no país e também permitiu correlacionar o discurso político com a ação. Trata-se de uma sistematização do transporte dentro do conhecimento geográfico, reconhecendo-o como um dos aspectos importantes neste novo período de intervenção estatal na fluidez nacional.
\end{abstract}

Palavras-Chave: transportes, investimentos, efeito multiplicador, PAC, desenvolvimento nacional.

\begin{abstract}
The transportation is a necessary condition to capital's circulation, therefore, it's also fundamental in production and reproduction of space. Based in tis assertive the paper objectify to perform an analysis about the fixed capital inversion, mainly in transportation work, made by federal government, through the Growth acceleration program investments. The investments in transportation, performed through the national intervention, can positively infer in job volume and effective demand, contributing to economic and social development. This analysis is based in the multiplication effect theory and idle capacity dialectic as means to learn the public investments relevancy in transportation infrastructure works. Such task brought with it the possibility to show what are the barriers to great public investments execution in the country and also allowed correlate the political speech to action. It is the transportation system inside the geographic knowledge, recognizing as one of the important aspects in this new national intervention period in national fluidity.
\end{abstract}

Key words: investments, multiplication effect, PAC, national development.

*Email: alessandrajulio@yahoo.com.br.

\section{Recommended Citation}

Silveira, M. R. and Julio, A. L. (2013) Os investimentos em transportes do Programa de Aceleração do Crescimento (PAC) e o efeito multiplicador brasileiro a partir do governo Lula da Silva. Journal of Transport Literature, vol. 7, n. 4, pp. $199-224$.

- JTL/RELIT is a fully electronic, peer-reviewed, open access, international journal focused on emerging transport markets and published by BPTS - Brazilian Transport Planning Society. Website www.transport-literature.org. ISSN 2238-1031. 


\section{Introdução}

Para um país com as dimensões do Brasil, é imprescindível uma infraestrutura que viabilize a integração econômica e social interligando de forma competente suas regiões. Sem meios de transporte a divisão social do trabalho é inexecutável, visto que ela supõe a movimentação de bens e pessoas. Sendo assim, a divisão do trabalho é uma importante condição para o desenvolvimento dos transportes e da indústria de transporte, os quais são partes constitutivas do processo de desenvolvimento econômico.

A fim de compreender como os investimentos em infraestruturas de transportes podem inserir positivamente no volume do emprego e na demanda, contribuindo para o crescimento - parte $^{1}$ do caminho necessário para um real desenvolvimento - foram utilizados as ideias e trabalhos elaborados por John M. Keynes (1985), sobre o Princípio da Demanda Efetiva, e Ignácio Rangel (2005), sobre a dialética da capacidade ociosa e crescimento econômico.

Com base nestes referenciais podemos relacionar a importância de um sistema econômico organizado de tal forma que gere expectativas de lucros à iniciativa privada (propensão marginal a investir), fazendo com que seus recursos ociosos sejam investidos. Esta organização passa por um planejamento estatal e investimentos, também estatais, em setores estratégicos como o transporte.

A fluidez do território nacional brasileiro respondeu, nas últimas décadas, às racionalidades impostas pelas necessidades do capital (internacional e nacional). Os investimentos do setor privado, após as concessões de serviços públicos à iniciativa privada, não refletiram em um aumento de investimentos em infraestruturas que compensasse o declínio dos gastos do setor público. E esta queda dos investimentos redundou em gargalos ao crescimento (IPEA, 2010). O resultado deste cenário foi um desenvolvimento desigual inter e intra-regional, com uma dupla ausência de integração: "a descontinuidade espacial no sentido da definição de uma economia nacional e a falta de complementaridade entre as diferentes modalidades de transporte" (Barat, 1978, p. 249).

\footnotetext{
${ }^{1}$ Apenas o crescimento do capital nacional não assegura a justa distribuição desta renda, de modo a diminuir as desigualdades presentes no Brasil.
} 
Nos últimos anos houve uma retomada dos investimentos públicos federais, principalmente com os projetos do Programa de Aceleração do Crescimento (PAC) e pela previsão de início de outras obras. Concomitantemente, as novas medidas de flexibilização da política fiscal e os investimentos públicos de médio e longo prazo estão acarretando um crescimento da economia nacional.

Respectivos investimentos em obras de transportes, além de contribuir para a economia, alteram e ampliam as interações espaciais. As interações espaciais, frutos das relações espaciais das quais as trocas fazem parte, permitem engendrar transformações no espaço social. Assim, se faz imperioso não apenas uma análise dos desdobramentos econômicos de referidos investimentos, mas também um estudo sobre a produção do espaço resultante destas novas interações espaciais.

A maioria dos estudos com fins de analisar a relação dos gastos públicos com investimentos em transporte e o crescimento econômico partem de modelos econômicos e dados quantitativos. Diferentemente, este artigo se configura como um esforço no estudo da relação entre os investimentos, os rebatimentos espaciais e o efeito multiplicador sobre à iniciativa privada, com base no exame e acompanhamento da execução de algumas obras do Programa de Aceleração do Crescimento. Neste intento, o artigo foi dividido em 2 seções. A primeira seção apresenta estudos importantes que salientam a relevância de inversões em transporte com destaque, em tópico específico, para o referencial teórico. A segunda seção descreve o PAC analisando mais atentamente algumas obras de maior destaque do programa, seja em função do retorno esperado, pela relevância nacional ou pelos problemas de execução do projeto. Ao final apresentam-se as conclusões.

\section{A importância dos investimentos em infraestruturas de transportes}

A reprodução e a acumulação do capital pressupõem a realização completa da circulação do capital. Nesse processo contínuo, o capitalista empreende uma busca ininterrupta pela máxima fluidez. Esta fluidez é alcançada através de um sistema coordenado de objetos: os fixos. Milton Santos (1997) deteve-se na análise dos fixos e dos fluxos e o papel dinâmico destes na redefinição do espaço social. 
"Os elementos fixos, fixados em cada lugar, permitem ações que modificam o próprio lugar, fluxos novos ou renovados que recriam as condições ambientais e as condições sociais, e redefinem cada lugar. Os fluxos são um resultado direto ou indireto das ações e atravessam ou se instalam nos fixos, modificando a sua significação e o seu valor, ao mesmo tempo em que, também, se modificam" (Santos, 1997, p. 53).

Assim, o modo de produção capitalista não apenas produz e reproduz a mercadoria e a maisvalia, mas também redefine o espaço; da mesma forma que o espaço enquanto instância social subordina as estruturas da sociedade. O espaço é, assim, um sistema de objeto e de ações resultado de determinadas condições históricas (Santos, 2005). Para além da discussão do espaço, Santos reconhece a inter-relação entre espaço, modo de produção e formação social. De modo que, "todos os processos que, juntos, formam o modo de produção (produção propriamente dita, circulação, distribuição, consumo) são histórica e espacialmente determinados num movimento de conjunto, e isto através de uma formação social" (Santos, 2005, p. 28). Destarte, a cada momento do modo de produção e da formação social a distribuição das infraestruturas e outras características do espaço irão interferir nas formações econômicas e sociais.

Os transportes permitem as interações espaciais, por isso condicionam os padrões de organização do território e a localização de atividades. O conceito de interações espaciais, nesse artigo, vai ao encontro das discussões e definições de Silveira e Cocco (2010). Os geógrafos realizam uma crítica às concepções econômicas e da geografia quantitativa que apreendem as interações espaciais mediante modelos de gravitação, baseados nos padrões da física newtoniana, ou seja, interações espaciais apenas como sinônimo de deslocamento da matéria no espaço. Nessa concepção o espaço geográfico é apenas receptáculo e não interage com o social. Por isso, os autores se utilizam das categorias, conceitos e leis do materialismo histórico e dialético para aprimorar o conceito de interações espaciais, dando a ele um caráter dialético em que as interações entre espaços através dos sistemas de transportes e comunicações transformam o espaço. 
A ação do Governo Federal e Estadual na implantação de infraestruturas de transportes, de forma geral, conduz a rebatimentos espaciais, na medida em que elas criam novas funções nos espaços, de acordo com a participação no sistema produtivo e na divisão territorial do trabalho.

Em seus escritos, Marx (1970) aponta que o principal aspecto no desenvolvimento do transporte é a redução do tempo de circulação do capital, como parte mesmo do desenvolvimento capitalista. Sendo o transporte um processo dentro da circulação capitalista, a determinação do valor nas atividades de transporte se realiza como qualquer outra mercadoria no modo de produção capitalista, ou seja, com geração de mais-valia. Assim, com base em Marx, se conclui que as atividades de transporte - ao permitirem a mais valia geram valor. Ou seja, são atividades em que há exploração do trabalho através da mais-valia e, por causa disso, está presente a teoria do valor-trabalho (Silveira, 2011).

O respectivo debate leva a compreender o papel das insfraestruturas no sistema de circulação, transporte e logística para garantir os fluxos internos, a dinamização da economia e o desenvolvimento regional. Temos que os fixos e os fluxos tendem a impulsionar mudanças na divisão territorial do trabalho, bem como gerar repercussões espaciais, por permitirem a interação espacial e a articulação de diversas escalas: a global, a supranacional, a nacional, a regional e a local.

Fromm (1968), ao discutir o papel dos transportes no desenvolvimento econômico, evidencia que os transportes criam economias internas para muitos setores e desenvolve a economia externa para todos os setores. $\mathrm{O}$ aumento da rede de transportes permite uma diminuição dos custos - também apontada por Marx (1970) -, um aumento da mobilidade e pode distribuir melhor a indústria, a renda e a população.

O geógrafo Ritter (1971), observando o papel dos transportes nos outros setores da economia, teceu alguns apontamentos para a Geografia dos Transportes, a saber: o tamanho dos mercados que representam os transportes e as telecomunicações exerce uma influência decisiva no crescimento econômico, incidindo sobre o volume e a estrutura de produção. Além disso, os transportes são um poderoso fator de inovação, isso pelo fato identificado por Marx (1970), de estes produzirem valor e serem capazes de extração de mais-valia. No Brasil, esta dinâmica do setor de transportes é evidente, principalmente, ao final da década de 1950. 
Os investimentos da indústria de transportes cresceram $80 \%$ nesta década, sendo um dos líderes da industrialização pesada e permitindo o favorecimento de indústrias acopladas e complementares, como a metal-mecânica (Tavares, 1998).

Estudos mais recentes buscam ratificar o papel dos transportes na economia e nas interações espaciais. Pini (1995), por exemplo, avança na discussão ao acrescentar mais um elemento, o político-administrativo. A contraposição entre transporte, economia e interesses políticos conduz a consolidação de diferenças de mobilidade e acessibilidade no território nacional, regional ou local.

Avaliando este argumento é inconcebível uma análise de obras públicas e/ou privadas como projetos individuais e isolados, sem incorporar as alterações na dinâmica espacial. Para Santos (2008), os objetos devem ser estudados juntamente com o seu entorno. "É o espaço que determina os objetos: o espaço visto como um conjunto de objetos organizados segundo uma lógica e utilizados segundo uma lógica" (Santos, 2008, p. 40). A referida lógica pode ser a do Estado (logística de Estado), a das grandes corporações (logística corporativa) ou a lógica das grandes corporações executada pelo Estado (quando o Estado atende aos interesses corporativos).

Dando continuidade a esta afirmação, Santos (2008) ressalta que os espaços redefinem os objetos técnicos, ao mesmo tempo observa que a propagação de novas tecnologias altera a divisão do trabalho e, por conseguinte, leva a mudanças territoriais. Ademais, sendo o transporte um agregador de valor aos produtos transportados, o capitalista procura formas para a diminuição dos custos de transporte, constituindo mais um impulso às inovações. Como buscou demonstrar Marx (1970), a melhoria dos meios de transporte e comunicação diminui o período de circulação da mercadoria e, em seguida, do tempo de rotação (tempo de produção + tempo de circulação).

As novas tecnologias organizacionais (logística) e o maior desenvolvimento dos fixos e dos meios podem diminuir os custos e encurtar as distâncias. Dentre os fatores organizacionais, as inovações em estratégias logísticas contribuem para a mobilidade e a abrangência de territórios. A alta tecnologia nos meios de transporte - como os contêineres; e os investimentos nos fixos - como as auto-pistas; redundam em agilidade no processo de circulação. 
A diminuição da distância representa a ampliação de comércio de mercadorias específicas, como as perecíveis, atendimento a demandas reprimidas e geração de novas demandas. Novos mercados consumidores e produtores se aliam ao sistema global, em uma relação que abrange toda uma cadeia de produção, de consumo e serviços. Todo esse processo tem repercussões espaciais, pois permite uma maior interação espacial.

À medida em que são instaladas ou melhoradas as infraestruturas de circulação, há estímulos à concentração espacial de empresas, ou seja, à formação de eixos de circulação econômica com fixos que permitem interações espaciais e, por conseguinte, alteram a dinâmica espacial e territorial. Ao discutirmos a desconcentração econômica no Estado de São Paulo, por exemplo, identificamos os eixos de circulação, principalmente as autoestradas, como um dos principais elementos determinantes para o processo de concentração. Isso porque são as infraestruturas, localizadas espacialmente, que geram e atendem as demandas reprimidas dos fluxos, possibilitando a acumulação de capitais, a divisão territorial do trabalho e a intensificação das inter-relações entre diferentes territórios, entre centros produtores e de demanda. Assim, as redes de transportes geraram e continuam gerando modificações na posição das cidades e das regiões, inclusive no desenvolvimento regional, já que interfere no contexto da concorrência entre as regiões, as quais buscam adquirir uma posição estratégica nestas novas redes (Pini, 1995).

Este processo de conflito de interesses entre diferentes territórios fica mais evidente quando se trata a análise pela ótica da reestruturação econômica, com foco na industrialização ${ }^{2}$. A lógica do capital busca regiões mais dinâmicas e com melhores infraestruturas ou regiões com maiores vantagens comparativas, contribuindo para a construção de um espaço descontinuo e fragmentado.

Os lugares, os territórios, desta forma, distinguem-se pela capacidade de oferecer rentabilidade aos investimentos. Para competir, as regiões se especializam, o que remete a

\footnotetext{
${ }^{2}$ A reestruturação econômica não tem só como foco a industrialização, mas todas as atividades produtivas. Todavia também não é só produtiva, pois atinge fortemente o setor de serviços e de comércio. Assim essa reestruturação é produtiva e de consumo.
} 
uma maior heterogeneidade entre as unidades territoriais, com uma maior divisão do trabalho $^{3}$. Consequentemente, se amplia a necessidade de interação entre os espaços.

Logo, temos que o sistema circulatório do capital, de forma geral, requer uma infraestrutura para circulação, transporte e estratégias logísticas. Neste sentido, não relacionar transportes, crescimento econômico e disparidades regionais é não compreender a totalidade do processo atuante para a estruturação do espaço nacional.

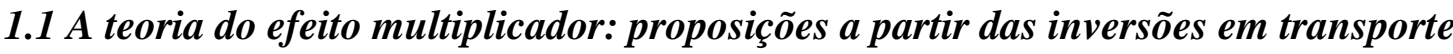

Para uma compreensão adequada da relevância do investimento em transporte - enquanto política setorial para a dinâmica econômica nacional - há as reflexões desenvolvidas por Ignácio Rangel (2005). Para o economista, o desenvolvimento brasileiro depende, em grande parte, da transferência de recursos ociosos da iniciativa privada para setores retardatários. Os investimentos em infraestrutura, por exemplo, podem fomentar um efeito multiplicador (efeito circular) interno que repercutirá positivamente na economia e na sociedade. Trata-se de uma reelaboração da teoria da demanda efetiva de Keynes aplicada à realidade brasileira.

A "saída keynesiana" pressupõe que o problema do sistema econômico está na insuficiência de demanda. Esta insuficiência inibe o processo de produção e o nível real do emprego. A demanda, de que trata o autor, é a demanda efetiva, ou seja, a renda agregada (ou produto) que os empresários esperam receber por meio do volume de emprego que resolvem conceber. Assim, os empresários ampliarão o número dos empregos de acordo com a expectativa de lucros futuros ${ }^{4}$. O princípio é definido por Keynes:

\footnotetext{
${ }^{3}$ Um bom exemplo pode ser observado em Santa Catarina. Nesse Estado o governo diminuiu as alíquotas de importações (via ICMS) pelos portos catarinenses. Assim, houve significativas mudanças urbanas e regionais na região de Joinville, Itajaí e Imbituba, ou seja, uma série de empresas importadoras (trades) se localizaram próximas aos portos, gerando investimentos, emprego, renda, interferindo no valor da terra rural e do solo urbano, entre outros fatores. Ainda, nessa lógica, as demandas da Petrobrás, por conta do Pré-Sal, contribuíram para diversas transformações espaciais em diferentes áreas do Rio de Janeiro, de Santa Catarina, do Rio Grande do Sul, de Pernambuco e até mesmo no Uruguai. Isso devido à montagem de uma série de estaleiros para as operações offshore.

${ }^{4}$ A despeito dos lucros futuros e da opção do empresário entre poupança e investimento tem particular interesse a afirmação de Tavares (1998): "Os lucros dependem do ritmo dos investimentos já realizados nos períodos anteriores; quanto mais investem 'no presente' mais lucrarão 'no futuro' e, portanto, mais poderão 'poupar' no tempo. Daí o aparente paradoxo de uma leitura keynesiana, estática, da igualdade entre Poupança e Investimento. $\mathrm{Na}$ verdade, em termos dinâmicos, quanto mais gastam (hoje) mais 'poupam' (depois) e quanto mais poupam (hoje) menos lucram, isto é menos poupam efetivamente (depois).
} 
"A quantidade de mão-de-obra $N$ que os empresários resolvem empregar depende da soma $(D)$ de duas quantidades, a saber: D1, o montante que se espera seja gasto pela comunidade em consumo, e D2, o montante que se espera seja aplicado em novos investimentos. Dé o que já chamamos antes de demanda efetiva" (Keynes, 1985, p. 32).

Portanto, são os investimentos correntes que determinarão o pleno emprego, levando a um aumento do fluxo de consumo (propensão marginal a consumir). Dada esta propensão a consumir, Keynes estabelece uma relação entre o fluxo dos investimentos e os volumes agregados de emprego e renda, cuja relação ele denomina "multiplicador" "E. "É pelo princípio geral do multiplicador que se deve explicar como as flutuações no montante dos investimentos, comparativamente pequenas em proporção à renda nacional, podem gerar alterações no emprego e na renda agregada de amplitude muito maior que elas próprias" (Keynes, 1985, p. 92). Os rendimentos dos trabalhadores empregados conduzem a um incremento na propensão marginal a consumir, ou seja, aumento da demanda. A ampliação da demanda pressupõe a ampliação dos fluxos e, por conseguinte, das interações espaciais, base para a produção e reprodução do espaço geográfico. No Brasil o problema não esta especificamente na insufiência de demanda, por isso avançamos no entendimento da teoria utilizando os estudos de Rangel (2005).

Ao invés de investimentos estatais via endividamento, via aumento de impostos ou diminuição de impostos, como previa Keynes, a "saída rangeliana", segundo Silveira (2007), propõe a alocação de recursos ociosos da iniciativa privada para investimentos nas infraestruturas básicas ou setores com anticapacidade ociosa.

Para Rangel os recursos ociosos (tanto recursos financeiros quanto meios de produção) estão mais na iniciativa privada do que no Estado. Todavia é o Estado brasileiro que deve redirecionar, através de parcerias público-privadas, esses recursos para os setores subinvestidos.

Rangel (2005), com uma leitura da economia nacional vinculada aos movimentos cíclicos do capitalismo mundial - ciclo Longo ou de Kondratieff (em torno de 40 e 60 anos) -, evidencia

\footnotetext{
${ }^{5}$ O conceito de multiplicador foi introduzido na teoria econômica por R. F. Kahn, em 1931 (Keynes, 1985).
} 
no advento do capitalismo industrial brasileiro a instauração dos ciclos nacionais, independentes dos ciclos longos. Assim, a "saída rangeliana" parte da identificação de que o Brasil vem se desenvolvendo através de vagas cíclicas, as quais possuem um fundo econômico-tecnológico e ocasionam mudanças sociais. Estes ciclos endógenos ${ }^{6}$, aproximadamente decenais, apresentam uma regularidade composta por uma fase expansiva, durante a qual um setor ou grupo de atividades econômicas expande-se até se pôr em excesso de capacidade; ao mesmo tempo, ocorrem alterações na estrutura da demanda, de modo que são expostos insuficiências e estrangulamentos, levando à fase recessiva. A superação da fase recessiva do ciclo exigirá investimentos, que por sua vez deverá utilizar o excesso de capacidade acumulada em um polo (Rangel, 2005).

Com efeito, a oposição dialética entre os dois polos (polo da capacidade ociosa e polo de investimentos futuros) exige que o Estado intervenha no sentido de orientar os fluxos financeiros de um polo para outro. O esforço do Estado em transferir a capacidade ociosa de um setor para outro deve se realizar entre o setor privado e o setor público. Sobretudo porque, ao final de um período de recessão, o Estado costuma manifestar uma grave deficiência financeira, inclusive devido à tensão ocasionada pela crise e tentativa do Estado em resolvêla. Este processo fica evidente em alguns períodos brasileiros como na depressão de 1962-65. Neste período, Rangel (2005) identifica a existência de uma capacidade ociosa nas atividades substituidoras de importações, ao passo que os grandes serviços de utilidades públicas se apresentavam como os setores com anticapacidade ociosa, tais como eletricidade, transportes ferroviário e marítimo, portos e transporte urbano básico, os quais foram base dos investimentos na década de 1970.

O mesmo ocorreu na década de 1980 com a crise da dívida do Estado, junto à comunidade financeira internacional. Realizando esta análise para a década de 1990, Pizzo (1998) assinala com capacidade ociosa os setores de equipamentos, construção e exportação; já como setores estrangulados aponta os setores de transporte, energia, água e esgoto, exatamente nos quais

\footnotetext{
${ }^{6}$ Os ciclos médios ou juglarianos interessam à economia brasileira de duas formas: como movimentos exógenos e endógenos. Os movimentos endógenos analisam as causas do ciclo no próprio processo econômico, visando demonstrar basicamente a formação e a transmissão de um processo cumulativo de alta ou baixa da economia. Para Rangel (1983, p. 41), no Brasil, as mudanças institucionais, a partir de 1920, "não se fizeram de chofre, mas através de aproximações sucessivas que, afinal, subdividiam o processo único de industrialização em processos parcelares, setoriais, a cada um dos quais correspondia um ciclo médio, isto é, um ciclo juglariano brasileiro".
} 
vieram incidir os projetos do PAC, lançado em 2007, no governo de Luiz Inácio Lula da Silva. Vale ressaltar que a cada ciclo endógeno os setores com capacidade ociosa se alteram.

Rangel propôs que, ao utilizar o potencial ocioso da iniciativa privada, aumenta-se o valor tributável e alivia o Estado dos encargos de alguns setores ineficientes (Silveira, 2007). Os recursos transferidos da iniciativa privada para áreas estranguladas aumentam a disponibilidade total de bens e serviços e, consequentemente, acarretam um aumento dos investimentos, possibilitando uma aceleração do desenvolvimento. Trata-se, genuinamente, de um "efeito multiplicador". Nestes termos, Rangel (2005) demonstra que o aumento do montante de investimentos está limitado a capacidade produtiva ociosa, independentemente da renda ou produto efetivo observado.

O "efeito multiplicador" a que se refere Rangel (2005) engloba toda a economia nacional. A transferência de capitais ociosos para investimento em infraestrutura impulsiona as indústrias de máquinas e equipamentos no mercado interno. A ampliação e a dinamização do mercado interno têm por consequências a geração de novos empregos, aumento da renda, consumo e poupança, ou seja, retomada do desenvolvimento econômico.

"Se uma economia não utiliza plenamente seus recursos produtivos, se deixa no limbo da mera possibilidade um produto adicional para o qual estão cumpridas as condições prévias materiais ou técnicas, renuncia a um adicional de riqueza que poderia, além de melhorar seus padrões de consumo, aumentar, o que é mais importante ainda, o volume dos seus investimentos, dos quais depende, em grande parte, a ulterior expansão do produto nacional, isto é, o desenvolvimento" (Rangel, 2005, p.467).

O Estado, ao transferir recursos de setores com capacidade ociosa para setores com anticapacidade ociosa, cria expectativas de lucros aos empresários e esta perspectiva, juntamente com uma baixa taxa de juros, induz a maiores investimentos, por parte do setor privado.

Vale ressaltar que quando há uma maior inversão de investimentos em obras de grande porte, como no caso das infraestruturas de transportes, há um incentivo para o aquecimento das indústrias de máquinas, matérias primas e peças. Portanto, a importação de equipamentos e 
tecnologia não contribui adequadamente para a circulação da economia nacional. A menos que tenha uma transferência de tecnologia com simultâneo treinamento de especialistas brasileiros, para que, num segundo momento, se utilize a produção nacional. Relacionado a isso, Rangel (2005) reitera que haverá aumento em termos reais se houver um aumento da oferta de bens de capital. A importação é válida também para reequipar com máquinas e equipamentos os setores não modernos da economia nacional, propiciando maior competitividade, joint ventures, entre outros, que estrategicamente ajudarão no desenvolvimento do país. Todavia, essas importações devem ter um caráter sazonal e dependente das estratégias econômicas da nação.

Ainda segundo Rangel (2005), os grandes meios de ação contra a ociosidade e a inflação são a expansão do comércio exterior, a mudança na estrutura da oferta e a mudança na estrutura de procura. Deve-se ter claro que o desenvolvimento depende de várias medidas: política cambial realista, uma política de incentivos fiscais e creditícios - orientando os investimentos privados para os setores estrangulados - e autonomia ao Governo Federal, para garantir a oferta de serviços básicos (Paim, 1998).

Somente o investimento em transporte não leva ao desenvolvimento. $O$ processo deve ser uma ação global, em diversos setores. O impulso para o desenvolvimento nacional e regional está relacionado a questões econômicas e sociais, remetendo a um planejamento nacional e não apenas a um planejamento setorial.

No regime neoliberal, com as estratégias para atrair investimentos externos, o governo aumentou as vantagens comparativas favorecendo a integração de cada uma de suas economias regionais (ou algumas de suas economias regionais) às redes globais e, como consequência, aprofunda as desigualdades territoriais. Assim, esses fenômenos acabarão "contribuindo para multiplicar os regionalismos e as forças desintegradoras da unidade nacional" (Fiori, 2001, p.133). Nas décadas de 1980 e 1990 foram poucos os espaços incorporados pelos de meios de circulação (Silveira, 2009).

O fim dos grandes projetos nacionais e o início da crise internacional e nacional tiveram um efeito direto e negativo sobre a indústria de diversos setores. Alguns setores como a indústria de bens de capital e as empresas especializadas em equipamento de transporte ferroviário 
eram altamente dependentes das empresas estatais. A estagnação e as incertezas internas e externas criaram um ambiente nada propício para investimentos privados.

Os investimentos, como indicava Keynes (1985), não são dispêndios para a economia nacional, mas estão associados à formação de expectativas de longo prazo. Assim, a diminuição das expectativas da iniciativa privada está correlacionada à redução dos investimentos que, por ventura, leva à retração do número de empregos e da demanda efetiva. Consequentemente, os estrangulamentos no setor de transporte são empecilhos ao desenvolvimento nacional e regional por limitar os fluxos econômicos, impelir a capacidade ociosa à indústria de transporte e outras indústrias correlacionadas e não impulsionar novas inversões em respectivas indústrias.

Não obstante, o diagnóstico prévio do PAC evidenciou que as carências e deficiências das infraestruturas brasileiras constituíam sério obstáculo ao crescimento e desenvolvimento nacional. Deste modo, este programa se configura como um primeiro passo na retomada dos grandes projetos, inclusive de transportes, vislumbrando desencadear efeitos positivos sobre a economia nacional e regional. Por outro lado, demonstra-se também que as iniciativas do PAC ainda representam uma iniciativa tímida diante das demandas por infraestruturas no Brasil e, em especial, de transportes.

\section{Os transportes no Programa de Aceleração do Crescimento e o multiplicador na economia nacional}

O Programa de Aceleração do Crescimento ${ }^{7}$ propôs medidas voltadas à melhoria da qualidade do gasto público e ao controle da expansão dos gastos correntes no âmbito da Administração Pública Federal. Ele é um programa interministerial e se caracteriza pela tentativa do Governo Federal de estabelecer metas para o crescimento (DIEESE, 2007).

$\mathrm{O}$ investimento em infraestruturas tem como objetivo eliminar gargalos que restringem o crescimento, reduzir custo e ampliar a produtividade estimulando o investimento privado e o desenvolvimento regional. Porém, o plano em si não pode ser caracterizado como um

\footnotetext{
${ }^{7}$ Instituído pelo Decreto n ${ }^{\circ} 6.025$, de 22 de janeiro de 2007.
} 
programa de desenvolvimento regional, mas tem o potencial de gerar significativos impactos regionais devido aos grandes investimentos propostos em determinadas regiões.

As obras escolhidas para compor o PAC foram selecionadas dentro de um conjunto de projetos setoriais baseados em alguns fundamentos, dentre eles: Planejamento Estratégico (fundamentado nas obras já previstas pelo Plano Nacional de Logística de Transporte - PNLT e pelo Plano Decenal do Setor Elétrico) e as Parcerias entre o setor público e o privado (nas Concessões Rodoviárias, Marinha Mercante, Ferrovias e Setor Energético) (Brasil, 2007). Em meio às obras selecionadas estão trechos da Ferrovia Norte-Sul (EF-151) e outras ferrovias de integração, trechos do Rodoanel de São Paulo, o Trem de Alta Velocidade, obras nos principais aeroportos, pavimentação e duplicação de algumas rodovias, construção de contornos ferroviários, incentivos à Marinha Mercante e concessão de trechos rodoviários. Muitas destas obras são antigos projetos nacionais que fizeram parte das promessas políticas em vários anos, como o Rodoanel, a Ferrovia Norte-Sul, o Ferroanel de São Paulo e melhorias em trechos rodoviários.

Com o fim dos investimentos nos sistemas de movimento, durante a década de 1990, a fluidez do território brasileiro ficou comprometida pelas várias viscosidades (Silveira, 2009). Na tipologia de Santos e Silveira (2006) às zonas de viscosidade são o oposto das zonas de fluidez. O descompasso entre a oferta de serviços infraestruturais e a demanda reprimida atingiu principalmente a malha rodoviária federal, os portos e as ferrovias. Realizando um comparativo entre o Governo de Fernando Henrique Cardoso e de Luiz Inácio Lula da Silva, observam-se vários avanços na política de transporte nacional, no sentido de concretizar projetos antigos e promover investimentos contundentes em infraestruturas, como no PAC e no PNLT, projetos que contribuem para ampliar os investimentos na construção e recuperação de ferrovias, rodovias e melhoram a integração nacional. Estes projetos ampliam a participação relativa dos investimentos em transportes, valores que seguiam um histórico decrescente nos últimos trinta anos. "O conjunto do setor de transportes investiu, em média, $2 \%$ do Produto Interno Bruto (PIB) na década de 1970, 1,5\% na de 1980 e menos de 0,7\% na de 1990" (Azeredo, 2004, p. 08).

De acordo com a teoria, o aumento da taxa de investimentos estimulados pelos projetos de infraestruturas tem potencial para desencadear efeitos positivos na economia brasileira. Tratase não somente de resolver gargalos ao escoamento da produção, mas de induzir uma cadeia 
de investimentos. Durante entrevistas realizadas com representantes de autarquias e empresas públicas, evidenciaram-se as discrepâncias entre o discurso e a prática na política nacional. Relacionada às obras de transportes, a questão nacional se limita ao texto do projeto, ou seja, não fica evidente uma articulação entre os diversos projetos assim como entre o Governo Federal e o Estadual. De modo que, por mais que o governo exponha um Projeto Nacional de Desenvolvimento, ele não se enquadra plenamente nos moldes que defendemos, pois a transferência de recursos ociosos para áreas antiociosas, os investimentos em infraestruturas e em diversos serviços públicos, a substituição setorial de importações e a política de comércio exterior ainda são tímidas.

No atual crescimento brasileiro, o estrangulamento do tráfego - como ocorre no sistema ferroviário e vias urbanas da Região Metropolitana de São Paulo ${ }^{8}$ (Silveira, 2009) e no setor aéreo nacional como demonstrou Camilo Pereira (2010) - se apresenta não apenas como limite à manutenção do crescimento como também prejudica a produtividade sistêmica. Paradoxalmente, as deficiências do transporte em algumas regiões do país e a falta de integração entre os modais também representam um obstáculo à competitividade, devido ao custo do transporte nacional.

Paralelamente às inversões públicas, é imperativo o desenvolvimento de um conjunto de projetos que estimulem a ampliação dos investimentos privados. Além disso, é necessário que a indústria nacional consiga suprir parte significativa da demanda, caso contrário haverá um crescimento das importações e não da economia nacional, principalmente quanto a bens de produção. Um exemplo ilustrativo deste argumento são os novos projetos ferroviários. $\mathrm{O}$ Brasil não fabrica trilhos, assim, todo o material para a Ferrovia Norte-Sul (EF 151) é importado, principalmente da China e da Polônia. Salienta-se que a China é um dos maiores importadores de minério de ferro brasileiro e o minério bruto representou $15 \%$ das exportações nacionais em 2010, segundo o Ministério do Comércio, Indústria e Serviço (2011). Com a expansão dos projetos ferroviários no Brasil, a discussão sobre a necessidade

\footnotetext{
${ }^{8}$ A maior parte das mercadorias com direção ao Porto de Santos atravessa a RMSP causando lentidão ao trânsito e contribuindo com outros problemas já existentes como: mobilidades (pessoas e mercadorias), problemas ambientais, sociais e de logística urbana e interurbana (Silveira, 2009). As cargas ferroviárias destinadas a Santos só podem cruzar a cidade, rumo ao porto, entre a meia-noite e às três horas da manhã em função do compartilhamento das vias com o tráfego dos passageiros o que eleva o preço de frete e compromete a eficiência do modal ferroviário (Campos Neto, Pêgo Filho, Romminger, Ferreira e Vasconcelos, 2010).
} 
de uma produção nacional voltou a entrar em pauta e, empresas como a Vale, estudam a produção de trilhos (Santos e Durão, 2011).

Um exemplo da conjuntura positiva sobre a indústria ferroviária é o renascimento desta indústria no município de Hortolândia/SP. Os projetos ferroviários para áreas urbanas e a previsão de obras no Brasil e, particularmente, na região de Campinas (como o Trem de Alta Velocidade) são alguns dos ensejos para a formação de uma cadeia produtiva da indústria ferroviária em Hortolândia e região. Segundo informações disponibilizadas pela Associação Brasileira de Indústrias Ferroviárias (Abifer), uma das primeiras grandes empresas do setor que se instalou na cidade foi a Construcciones y Auxiliar de Ferrocarriles (CAF), em 2009, seguida pela instalação de outra gigante do setor: a AmstedMaxion (Abifer, 2011).

A retomada das inversões públicas é responsável também pela geração e/ou ampliação de outros polos de produção de trens, implementos ferroviários e peças. Apesar da maioria destes se concentrarem nos estados de São Paulo, Minas Gerais e Rio de Janeiro, também existem iniciativas no Ceará e em Pernambuco. Neste contexto, a construção de novos trechos ferroviários vai além de resolver gargalos infraestruturais, assim como não se limita ao escoamento de commodities; também contribui para a integração nacional e para a expansão da indústria atrelada (CNT, 2011). "Por otra parte, constituye una actividad capaz de generar un alto volumen de empleos directos, pero, también, de empleos indirectos en sectores tales como, la actividad industrial, los materiales, etc." (Pons e Reynes, 2004. p. 220). O respectivo processo ocorre também em outras obras de infraestrutura de transporte, saneamento e energia.

Apesar da importância das inversões no sistema ferroviário pelo PAC 1 em estudo Campos Neto, Pêgo Filho, Romminger, Ferreira e Vasconcelos (2010) inferem que o programa cobre 50\% das necessidades ao modal apontadas pelo Mapeamento IPEA de Obras Ferroviárias. Não obstante, os autores ressalvam que muitas das obras imprescindíveis ao setor são de responsabilidade das concessionárias e não do Governo Federal, como obras de recuperação e ampliação. Por outro lado, existem obras que são típicas do poder público como os contornos ferroviários, novas ferrovias e ampliação da malha, os quais contribuem principalmente com o bem-estar social devido ao descongestionamento do tráfego urbano.

\footnotetext{
${ }^{9}$ Por outro lado, constitui uma atividade capaz de gerar um alto volume de empregos diretos, mas também empregos indiretos, em setores como a atividade industrial, materiais, etc. (Pons e Reynes, 2004. p. 220).
} 
Um ponto importante a destacar nas obras ferroviárias financiadas pelo PAC é a extensão dos beneficiados, ou seja, são obras que transcendem as linhas regionais e, portanto, são de interesse nacional e justificam a intervenção da União. Com efeito, a ampliação da malha ferroviária e concomitante dinamização econômica se materializarão em maior divisão territorial do trabalho e novas organizações no espaço nacional.

Ignácio Rangel reconhecia no esforço de substituição de importações um movimento que, longe de equalizar a balança de pagamentos, ampliava a procura nacional de bens importados. "Graças a isso, o desequilíbrio que está no ponto de partida do esforço de substituição, que resulta no desenvolvimento, longe de se resolver, tende a perpetuar-se, tornando imperativa novas substituições, e, portanto, gerando novo ciclo de desenvolvimento" (Rangel, 2005, p. 184). A ação do Estado, enquanto planejador, está exatamente em cuidar da relação de substituição de importações, usando-se da capacidade ociosa não utilizada nas indústrias nacionais. Também está na utilização das importações de bens ainda não produzidos no país ou que ainda não seja interessante à produção. A lógica posta por Rangel é o planejamento, o projetamento pelo Estado do desenvolvimento através de concessões, estatizações, substituições setoriais de importações, parcerias entre o público e o privado, controle cambial e outros atributos que um Estado forte, planejador e sob o "ponto de vista nacional" pode executar.

O crescimento da demanda do mercado doméstico e do transporte de carga aérea nos últimos anos não foi acompanhado por um simultâneo planejamento das infraestruturas aeroportuárias e aeronáuticas. O eixo Rio de Janeiro-São Paulo é um dos trechos com grandes problemas de fluidez, não apenas no sistema aéreo. A solução proposta pelo Governo Federal é a construção do Trem de Alta Velocidade (TAV) ligando as duas metrópoles. No projeto consta ainda a construção do trecho São Paulo-Campinas. O acesso à metrópole de Campinas possibilitará a viabilização do aeroporto de Campinas como alternativa aos aeroportos de Congonhas e Guarulhos. Ambos os aeroportos apresentam problemas de esgotamento da capacidade e impossibilidades de grandes ampliações devido à forte urbanização da vizinhança.

O projeto TAV brasileiro terá um alto custo porque o traçado atravessará grandes áreas urbanas, regiões de serra e reservas ambientais; somente o custo de desapropriações já será bem alto, considerando o traçado referencial proposto pela Agência Nacional de Transporte Terrestre (ANTT). Uma opção que se adaptaria melhor à realidade brasileira seria um trem 
combinado, ou seja, uma integração entre diferentes trens. O compartilhamento dos trilhos e a integração de trens ampliariam o número de estações e gerariam uma rede que pode atender a um número maior de passageiros a fim de diminuir o valor das passagens e atender um maior público. A integração requer trens com velocidades menores, ou seja, mais estações, que alimentem o trem de alta velocidade. Esse modelo poderia atender a demanda existente, não apenas no sistema aeroviário, mas principalmente no sistema rodoviário. A conexão com outros modais também facilitaria a conexão e a mobilidade.

De acordo com o Plano Plurianual (2008-2011), o TAV promoverá três "ondas" de efeitos econômicos. A primeira será a criação de centros comerciais nas estações. A segunda abarca os empreendimentos imobiliários nas imediações das estações, entre condomínios residenciais e escritórios. A terceira se refere à construção de avenidas, novos pontos de ônibus e a construção de metrôs que darão acesso ao TAV (Campos Neto, Pêgo Filho, Romminger, Ferreira e Vasconcelos, 2010). Estas obras correlacionadas podem gerar encomendas para diferentes indústrias. Trata-se, pois, de uma questão de planejamento de longo prazo.

Do ponto de vista social e urbano um trem de alta velocidade aproxima os lugares e altera a relação espaço-tempo, de um tempo "natural” para um tempo "rápido", como consequência ele dá um novo caráter às interações espaciais. Este tipo de projeto também causa grandes transformações no uso e ocupação do solo nas áreas de seu traçado (Lacerda, 2008). De forma geral, inversões em infraestruturas de transportes ocasionam aumento do valor da terra nas áreas em torno da construção, o que acarreta uma especulação imobiliária.

A despeito de todos os problemas técnicos da referida obra, a construção do TAV permitirá a obtenção de uma tecnologia que o país não possui. A industrialização pelo modelo de substituição de importações - enquanto resposta nacional frente às crises da economia mundial - demonstrou a capacidade de avanço das forças produtivas do Brasil diante das importações. Entrementes, para Rangel (2005, p. 337), “[...] antes de nos tornarmos produtores de tecnologia, devemos constituir-nos em sistemáticos importadores dessa mercadoria", isto é, um novo ciclo de formação de capital baseado em um novo produto da cesta de consumo nacional.

Outro gargalo do transporte brasileiro está nos portos. O Porto de Santos como o maior porto da América Latina serve para o escoamento de produtos de vários estados e grande parte desta 
produção atravessa a região metropolitana de São Paulo, consequentemente obras que facilitam o acesso ao porto não são apenas de interesse paulista. Para Pons e Reynes (2004), o sistema portuário desempenha papel fundamental no desenvolvimento econômico nacional e regional. Neste contexto, o PAC definiu recursos para as obras da Avenida Perimetral, margem esquerda (Guarujá), margem direita (Santos) e aprofundamento do calado. No total de investimentos do PAC foram destinados $\mathrm{R} \$ 63,2$ milhões (77\%) na obra da Implantação da Avenida Perimetral Portuária e R\$ 12,3 milhões na Dragagem de Aprofundamento do Porto de Santos (Codesp, 2009).

O governo do município de Santos, acompanhando os novos investimentos da iniciativa privada nos portos e observando os novos investimentos, fruto da exploração do pré-sal na Bacia de Santos pela Petrobrás, realizou uma revisão do zoneamento do município a fim de ampliar a região apta a receber empreendimentos portuários. Esta ação também está atrelada ao projeto de duplicação do porto (Pires, 2011).

O aumento da movimentação de carga de 2010 em comparação com 2009 (34,7\% somente nas importações), em função do crescimento econômico, refletiu em uma busca por aumento da capacidade dos terminais. A maioria dos terminais do Porto de Santos está realizando ampliações, muitas obras com aporte de recursos públicos, como é o caso do Terminal para Contêineres da Margem Direita S.A. (Tecondi).

Estão em construção mais dois terminais para contêineres e líquidos em Santos. Um pela Empresa Brasileira de Terminais Portuários S.A. (Embraport) e outro pela Brasil Terminal Portuário - BTP. A estimativa é que "Juntos, BTP e Embraport quase duplicarão a atual oferta de contêineres em Santos, para 5,6 milhões de TEUs (contêiner de 20 pés) até o fím de 2013, quando a primeira fase dos dois terminais estarão concluídas [...]” (Pires, 2011). A matriz de transporte regional deverá se adequar ou esse aumento da capacidade do porto ficará comprometido, ou pior, causará ainda mais congestionamentos no acesso terrestre e marítimo.

A expansão do porto e os novos investimentos interferem em processos de valorização e desvalorização de áreas do município, ou seja, uma reorganização do espaço, tendo o poder público como promotor. O desenvolvimento de áreas produtivas impõe novos desafios às cidades portuárias, como as questões ambientais e socioeconômicas demandando políticas públicas para a gestão da cidade e do porto. A perspectiva de crescimento na movimentação 
nos portos permite também o crescimento da cadeia produtiva do segmento da indústria naval, com geração de demandas por serviços de apoio portuário, estudo e geração de novas tecnologias, entre outros serviços, com consequente efeito multiplicador sobre a economia de forma geral, gerando novos empregos. A indústria naval foi um dos segmentos que nas últimas décadas passou por um processo de desmantelamento e alta capacidade ociosa, em consequência algumas fábricas passaram a produzir máquinas e equipamentos para outros setores (Castro, 2011).

Assim, as inversões no setor de infraestrutura, tanto por parte da União quanto da iniciativa privada, estão impulsionando o desenvolvimento tecnológico, a reativação e montagem de estaleiros, construções ferroviárias, portos, estradas e outros. Por conseguinte, toda a cadeia produtiva (siderúrgicas, fundição, fabricação de vagões e fornecedoras de concreto, dormentes, cimento) é afetada e criam-se novas oportunidades de emprego e renda. Os novos assalariados gastarão parte da renda com bens de consumo, aquecendo outros setores econômicos como comércio e serviços.

\section{"[...] Ao atingir uma parcela da população, há a reprodução dos benefícios} sobre toda a comunidade, pois o efeito multiplicador tem resultado sobre a renda. Portanto, quanto maior a propensão a consumir (parte da renda que é despendida em consumo), maior será a renda e mais eficaz o efeito multiplicador" (Silveira, 2007, p. 164).

Está evidente no encerramento do período para conclusão do PAC 1 e no caminhar das obras do PAC 2 que as obras não estão dentro do prazo estipulado e nem são no montante necessário, conforme se defende nesse artigo. No entanto, parte dos objetivos do PAC, como induzir e estimular o investimento privado (propensão marginal a investir) começa a dar os primeiros resultados em um cenário econômico mundial primeiramente favorável e depois de crise. Ainda o PAC apresenta-se como um cenário macroeconômico de expectativas de lucros aos empresários. "Note-se que a produtividade social pode crescer antes da maturação do projeto em realização pelo que a própria inversão terá sobre os custos unitários das demais indústrias. A inversão é, pois, duplamente necessária à economia [...]” (Rangel, 2005, p. 190).

Os investimentos públicos federais mais que dobraram, subindo de 1,4\% do PIB no início de 2004 para cerca de 3,3\% em agosto de 2010 (IPEA, 2010). Em 2010 o crescimento 
acumulado do PIB (7,5\%) foi o mais elevado desde 1986. Através da Tabela 1 podemos evidenciar o cenário macroeconômico brasileiro nos últimos anos.

Tabela 1 - Dados da economia brasileira nos anos entre 2007-2012 ${ }^{10}$.

\begin{tabular}{l|l|l|l|l|l|l}
\hline Indicadores & $\mathbf{2 0 0 7}$ & $\mathbf{2 0 0 8}$ & $\mathbf{2 0 0 9}$ & $\mathbf{2 0 1 0}$ & $\mathbf{2 0 1 1}$ & $\mathbf{2 0 1 2}(\mathbf{1})$ \\
\hline PIB (R $\$$ bilhões) & $2.661,3$ & $3.032,2$ & $3.239,4$ & $3.770,1$ & $4.143,0$ & $4.214,3$ \\
\hline Taxa de Variação Real (\%) & 6,1 & 5,2 & $-0,3$ & 7,5 & 2,7 & 1,9 \\
\hline Indústria & 5,3 & 4,1 & $-5,6$ & 10,4 & 1,6 & 0,7 \\
\hline Serviços & 6,1 & 4,9 & 2,1 & 5,5 & 2,7 & 2,1 \\
\hline $\begin{array}{l}\text { Formação Bruta de Capital Fixo } \\
(\%)\end{array}$ & 13,9 & 13,6 & $-6,7$ & 21,3 & 4,7 & 2,1 \\
\hline Investimento (\% do PIB) & 17,4 & 19,1 & 18,1 & 19,5 & 19,3 & 19,1 \\
\hline Consumo Final - Famílias** & 6,07 & 5,67 & 4,44 & 6,94 & 4,09 & - \\
\hline
\end{tabular}

A partir de 2007 houve um aumento significativo no valor do PIB nacional, com uma variação positiva em outras variáveis essenciais no processo de desenvolvimento brasileiro, como o aumento na taxa de investimento e crescimento do consumo das famílias. Estes dados evidenciam um mercado em expansão, com um aumento da demanda agregada e das expectativas de lucros, ainda mais com o novo governo assumindo a continuidade das obras referente ao PAC 1 e a execução dos projetos constantes no PAC 2. Os dados apresentam queda em 2009 em função da crise de 2008, mas em 2010 os indicadores retomam uma taxa de crescimento.

A ampliação das inversões públicas e privadas também gera transformações no espaço geográfico, na medida em que não se trata apenas de modificações nos fixos, mas também nos fluxos e, por conseguinte, nas interações espaciais. As interações criam novas ou ampliam antigas funções nos espaços, de acordo com a participação no sistema produtivo e na divisão territorial do trabalho.

Tomando a Ferrovia Norte-Sul (EF 151) como exemplo, observamos que o prolongamento desta ferrovia, ligando a região Norte do país com a região Sul e Sudeste, abre a possibilidade de escoamento de produtos do Centro-Oeste e mesmo do noroeste de São Paulo pelos portos do Norte do país. A articulação entre diferentes regiões proporciona um aproveitamento e melhora a distribuição de recursos, geração de divisas, trocas entre o mercado interno e novas

\footnotetext{
${ }^{10}$ Fonte: IBGE, Banco Central, IPEA. *Preços de mercado. Obs.: dados do IBGE apresentados segundo a nova metodologia de cálculo. (1) $1^{\circ}$ trim de 2012, acumulado nos últimos 12 meses. ** Variação real anual.
} 
oportunidades de trabalho, durante a construção da mesma e após. Na avaliação de Pochmann (2010), o conjunto dos investimentos do PAC contribui para o fortalecimento das atividades econômicas em áreas de vazio produtivo, contribuindo para reduzir o grau de concentração da renda na região centro-sul, com um reforço positivo à integração nacional.

Os projetos de investimentos do Governo Federal são importantes para um sistema articulado de movimento e circulação no país, para a mobilidade e interações espaciais e, sobretudo, no sentido de ampliar a eficácia marginal do capital e o emprego.

Se o país continuar com o crescimento do PIB identificado nos últimos anos e o sistema de movimentos não acompanhar este crescimento, haverá em alguns anos um "apagão infraestrutural e logístico", pois a otimização dos fluxos através das estratégias logísticas tem um limite e esse limite é a falta de infraestruturas de transportes (Silveira, 2011). Reafirma-se, deste modo, a relevância dos projetos como o PAC, os quais buscam alternativas para incrementar a fluidez territorial e aprimorar a logística e a circulação regional e nacional. Entretanto, o PAC não prevê investimentos para a totalidade das deficiências existentes e, apesar do crescimento econômico ampliar a propensão marginal, o investimento da iniciativa privada do setor ainda carece de inversões. Além disso é necessária uma maior eficiência e agilidade na gestão dos investimentos previstos no programa e maior obediência aos cronogramas. Algumas das obras do PAC 1 que estavam previstas para conclusão em 2010 foram finalizadas em 2012. O IPEA (2010) também faz referência aos problemas burocráticos que causam lentidão na entrada e liberação das cargas. 


\section{Conclusão}

O presente artigo trouxe algumas implicações do Programa de Aceleração do Crescimento na economia nacional. O estudo vinculou a Geografia Econômica e a Geografia da Circulação, Transportes e Logística, reconhecendo a circulação e as interações espaciais como relevantes na produção do espaço. Para fundamentar o estudo realizou-se uma revisão bibliográfica sob a relevância dos investimentos em transportes para a dinâmica econômica e fluidez do espaço.

Assim, observou-se que investimentos no setor de transporte são importantes para o país, uma vez que estrangulamentos neste setor são obstáculos à integração nacional, consequentemente para as interações espaciais, para a dinamização do mercado interno e para a geração de demanda em diferentes setores da economia. Além disso, os produtos nacionais perdem muito em competitividade com os altos custos do transporte nacional.

No desenvolvimento do artigo a teoria do efeito multiplicador, utilizada a partir das contribuições de Rangel (2005), permitiu estabelecer uma relação entre as inversões por parte do Estado e a utilização da capacidade ociosa na iniciativa privada e/ou a criação de nova capacidade produtiva. A ação do governo, em relação às obras do PAC, remonta a aspectos da análise de Rangel. O Estado não tendo recursos para financiar todos os projetos de infraestrutura e dos meios de consumo coletivos deve realizar concessões e parcerias públicoprivadas.

Dentro das conclusões auferidas, consideramos que a maior contribuição do PAC 1 foi recuperar a questão do investimento em infraestrutura. Uma maior inversão de investimentos em obras de grande porte geram incentivos para o aquecimento das indústrias de máquinas, matérias primas e peças, devido ao aumento da demanda. Tais investimentos podem ocasionar o aumento do emprego, da renda e do consumo urbano que, por conseguinte, fomenta o crescimento da indústria, principalmente na indústria de bens de consumo duráveis, um verdadeiro efeito multiplicador.

Tomam-se, por exemplo, algumas obras do PAC para demonstrar os efeitos sobre a demanda efetiva na organização do espaço geográfico. O setor ferroviário é, com certeza, o que apresenta maiores expectativas frente aos anúncios do Governo Federal e, consequentemente, está em ampla expansão. A Marinha Mercante também segue em ampliação devido ao 
crescimento nacional e aos novos projetos petrolíferos. Essas obras e as demais trazem conjuntamente benefícios para toda economia nacional, pois geram um efeito multiplicador em diferentes ramos da indústria e na iniciativa privada, além de diminuir o Custo Brasil nos produtos nacionais.

Contudo, outro diagnóstico a respeito das obras selecionadas foi o fato de se tratar de obras antigas dentro dos projetos políticos. A maioria delas já consta nas promessas políticas desde o período do Estado desenvolvimentista. Logicamente, nesse período os projetos foram retomados e alterados várias vezes perfazendo uma série de estudos e gastos públicos. Tal fato remete à questão do discurso político e o uso de projetos para campanhas políticas. No Brasil, esse artifício é bastante utilizado, sendo assim, mais um motivo para a construção de um projeto nacional que extrapole os limites de um governo balizando a ação do Estado sob a atuação de diferentes governos.

Apesar dos problemas apontados os resultados do PAC, a partir de 2005, mostraram um aumento significativo na taxa de crescimento nacional, com simultânea variação positiva em outras três variáveis essenciais no processo de desenvolvimento brasileiro, a saber: o aumento na taxa de investimento, a aceleração das taxas de crescimento do consumo doméstico e a queda da inflação. Estes dados evidenciam um mercado em expansão, com um aumento da demanda agregada e das expectativas de lucros. Todavia, em 2012, as expectativas do PIB diminuíram e, mesmo com o PAC Copa e o PAC Olimpíadas, os investimentos em infraestruturas não foram capazes de resolver o problema da estagnação do crescimento econômico, como ocorreu na época do Milagre Econômico (1967-1974).

A manutenção da taxa de crescimento e das expectativas de lucro depende de uma conjuntura nacional e internacional, mas a permanência das inversões em projetos de médio e longo prazo pela União é basilar para o desenvolvimento nacional, principalmente com a mobilização de investimentos para os grandes serviços de utilidade pública.

Considerando a construção do trabalho evidenciamos as dificuldades de se trabalhar com projetos da União, particularmente com um objeto de pesquisa que ainda está em construção, o PAC. Tal tarefa trouxe consigo a possibilidade de demonstrar quais os entraves à execução de grandes investimentos públicos no país e também permitiu correlacionar o discurso 
político com a ação - ainda que este aspecto não tenha sido aprofundado no artigo - ele apenas balizou as conclusões.

\section{Referências}

Associação Brasileira de Infraestrutura Ferroviária - ABIFER (2004) Hortolândia se destaca como polo produtivo de trens. Disponível em: www.abifer.org.br.

Azeredo, L. C. L. de. (2004) Investimento em infra-estrutura no plano plurianual (PPA) 2004-2007 uma visão geral. Texto para discussão, n. 1024. Brasília: IPEA, junho.

Barat, J. (1978) A evolução dos transportes no Brasil. Rio de Janeiro: IBGE/IPEA.

Brasil (2007) Programa de Aceleração do Crescimento. Brasília. Disponível em: www.brasil.gov.br/pac. Acessado em: 08 fev. 2010.

Brasil - Ministério do Desenvolvimento, Indústria e Comércio Exterior (2011) AliceWeb. Disponível em: www.mdic.gov.br. Acesso: em 03 nov. 2011.

Camilo Pereira, A. P. (2010) Transporte Aéreo Regional no Estado de São Paulo. Dissertação (Mestrado em Geografia) Faculdade de Ciência e Tecnologia, Universidade Estadual Paulista, Presidente Prudente.

Campos Neto, C. A. S., Pêgo Filho, B., Romminger, E. A., Ferreira, I. M. e Vasconcelos, L. F. S. (2010) Gargalos e demandas da infraestrutura ferroviária e os investimentos do PAC: mapeamento IPEA de obras ferroviárias. Texto para discussão, n. 1465. Rio de Janeiro: IPEA, jan.

Castro, G. de. (2011) Momentos oportunos para os fabricantes. Valor Setorial - Indústria Naval, pp. 71-73.

Companhia Docas do Estado de São Paulo - CODESP (2009) Relatório Anual. Disponível em: www.portodesantos.com.br/relatorio.php.

Confederação Nacional do transporte - CNT (2011) Pesquisa CNT de Ferrovias 2011. Brasília.

Corrêa, R. L. (1997) Interações Espaciais. In: Castro, I. E. de., Gomes, P. C. da C., Corrêa, R. L. (Orgs.). Explorações geográficas. Rio de Janeiro: Bertrand Brasil, pp. 279-314.

Fiori, J. L. (2001) Brasil no espaço. Petrópolis: Vozes.

Fromm, G. (1968) Transporte e desenvolvimento econômico. Rio de Janeiro: Victor Publicações LTDA.

Instituto de Pesquisa Econômica Aplicada - IPEA (2010) Brasil em Desenvolvimento: Estado, planejamento e políticas públicas. Brasília: IPEA, vol. 3.

Keynes, J. M. (1985) A teoria geral do emprego, do juro e da moeda: inflação e deflação. $2^{\mathrm{a}}$ ed. São Paulo: Nova Cultural.

Lacerda, S. M. (2008) Trem de Alta Velocidade: Experiência Internacional. Revista do BNDES, Rio de Janeiro, vol. 14, n. 29, pp. 61-80.

Marx, K. (1970) O Capital: crítica da economia política. Livro Segundo. Rio de Janeiro: Civilização Brasileira.

Paim, G. (1998) Ignácio Rangel: um intérprete original da realidade brasileira. In.: Mamigonian. A. Rego, J. M. (Orgs). O Pensamento de Ignácio Rangel. São Paulo: Editora 34. 
Pini, G. (1995) La géographie des transports. In. Bally, A. S. Les conceptos de La géographie humaine. Masson: Paris Milan Barcelonr, pp. 175-185.

Pizzo, M. do R. (1998) Rangel e a concessão de serviços públicos à iniciativa privada. In.: Mamigonian. A., Rego, J. M. (Orgs). O Pensamento de Ignácio Rangel. São Paulo: Editora 34, pp. 37- 68 .

Pochmann, M. (2011) Os desafios do Estado na construção do desenvolvimento. Disponível em: www.cartacapital.com.br.

Pons, J. M. S. e Reynes, J. M. M. (2004) Geografía de los Transportes. Palma de Mallorca, Universitat de les Illes Balears. Madri: Ariel.

Rangel, I. (2005) Obras Reunidas. Rio de Janeiro: Contraponto.

Ritter, J. (1971) Géographie des transports. Paris: PUF.

Santos, M. (1997) Pensando o espaço do homem. São Paulo: Hucitec.

Santos, M. (2008) A natureza do espaço. Técnica e Tempo. Razão e Emoção. São Paulo: Edusp.

Santos, M. (2005) Da Totalidade ao lugar. São Paulo: Editora da Universidade de São Paulo. (Coleção Milton Santos; 7).

Santos, M e Silveira, M. L. (2006) O Brasil: território e sociedade no início do século XXI. $5^{\mathrm{a}}$ ed. Rio de Janeiro: Record.

Santos, C e Durão, V. S. (2011) Vale estuda montar uma fábrica de trilhos em Minas Gerais. Valor Econômico, 10/08/2011, São Paulo.

Silveira, M. R. (2007) Estradas de ferro do Brasil: das primeiras construções às Parcerias PúblicoPrivadas. Rio de Janeiro: Interciência.

Silveira, M. R. (2009) Logística, sistemas de movimento, fluxos econômicos e interações espaciais no território paulista: uma abordagem para a geografia dos transportes e circulação. Revista Scripta Nova, Barcelona, v. XIII, n. 283.

Silveira, M. R. (2011) Geografia da Circulação, Transportes e Logística: construção epistemológica e perspectivas. In: Silveira, M. R. (Org.). Circulação, Transportes e Logística: diferentes perspectivas. 1ed. São Paulo: Outras Expressões, pp. 21-67.

Silveira, M. R. e Cocco, R. G. (2010) Interações espaciais, transporte público e estruturação do espaço urbano. Revista Brasileira de Estudos Urbanos e regionais. Associação Nacional de PósGraduação e Pesquisa em Planejamento Urbano e Regional São Paulo, vol. 12, n. 1, pp. 63-82.

Tavares, M. da C. (1998) Ciclo e crise: o movimento recente da industrialização brasileira. Campinas: Unicamp.

Ullman, E. (1972) Geography as spatial interaction. In: Hurst, M. E. (org.). Transportation Geography. Londres: Macgraw Hill, pp. 29-39. 